\title{
Characteristics associated with activity restriction induced by fear of falling in community-dwelling elderly
}

\author{
Características associadas à restrição de atividades \\ por medo de cair em idosos comunitários
}

Rosângela C. Dias', Maria T. F. Freire², Érika G. S. Santos², Renata A. Vieira³, João M. D. Dias', Mônica R. Perracini

\begin{abstract}
Objectives: The aim of this study was to determine the social-demographic, clinical, functional and psychological factors associated to activity restriction due to fear of falling in community-dwelling elderly and identify which variables best discriminate groups of elderly with different levels of activity restriction and fear of falling. Methods: One hundred and thirteen community-dwelling elderly ( $74.5 \pm 7$ years old) participated in the study. Activity restriction induced by fear of falling, previous falls, fall related self-efficacy, frailty phenotype, functional capacity, depressive symptoms, health self-perception, socio-demographic and clinical factors were assessed. Descriptive statistics, chisquare, ANOVA and Kruskal Wallis tests were used to analyze the associations between activity restriction due to fear of falling and all other variables. Path analysis (CHAID) method was used to verify which variables better discriminated groups in relation to activity restriction $(\alpha=0.05)$. Results: The participants who reported fear of falling and activity restriction demonstrated higher depression $(p=0.038)$, lower fall related self-efficacy $(p<0.001)$, lower gait velocity $(p=0.043)$ and independence level for instrumental daily living activities $(p=0.017)$, higher number of diseases $(p=0.048)$, worse health self-perception $(p=0.040)$ and more depressive symptom $(p=0.023)$. The best variables to discriminate groups were depression $(p=0.004)$, exhaustion (frailty phenotype) $(p=0.010)$ and social participation activities $(p=0.016)$. Conclusion: Activity restriction due to fear of falling may have negative effects on functional capacity and psychological aspects in community-dwelling elderly. Psychosocial factors seem to better discriminate the elderly who avoid activities due to fear of falling.
\end{abstract}

Keywords: activity restriction; fear of falling; fall; aged; physical therapy.

\section{Resumo}

Objetivos: Determinar os fatores sociodemográficos, clínicos, funcionais e psicológicos associados à restrição de atividades por medo de cair em idosos comunitários e identificar quais variáveis melhor discriminam os grupos em relação à restrição de atividades por medo de

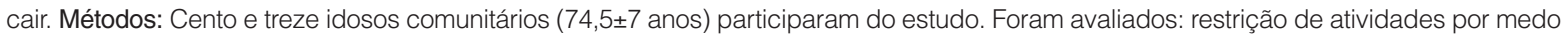
de cair, história de quedas, autoeficácia relacionada às quedas, fenótipo de fragilidade, aspectos sociodemográficos e clínicos, capacidade funcional, depressão e autopercepção de saúde. Estatísticas descritivas, teste qui-quadrado, ANOVA e o teste Kruskal-Wallis foram utilizados para analisar as relações entre a restrição de atividades por medo de cair e as outras variáveis. O método Chi-Square Automatic Interaction Detection (CHAID) foi utilizado para verificar quais variáveis melhor discriminavam os grupos em relação à restrição de atividades $(\alpha=0,05)$. Resultados: Idosos que relataram restrição de atividades por medo de cair apresentaram maior autorrelato de depressão ( $p=0,038)$, menor autoeficácia em relação às quedas $(p<0,001)$, menor velocidade de marcha $(p=0,043)$ e nível de independência para realização de atividades instrumentais de vida diária $(p=0,017)$, maior número de doenças $(p=0,048)$, pior autopercepção de saúde $(p=0,040)$ e maior presença de sintomatologia depressiva ( $p=0,023)$. As variáveis que melhor discriminaram os grupos foram depressão $(p=0,004)$, exaustão (fenótipo de fragilidade) $(p=0,010)$ e participação em atividades sociais $(p=0,016)$. Conclusão: A restrição de atividades por medo de cair pode ter efeitos negativos na capacidade funcional e nos aspectos psicológicos de idosos comunitários. Fatores psicossociais parecem discriminar melhor os idosos que apresentam restrição de atividades por medo de cair

Palavras-chave: restrição de atividades; medo de cair; queda; idoso; fisioterapia

Received: 03/30/2011 - Revised: 05/19/2011 - Accepted: 05/30/2011

${ }^{1}$ Physical Therapy Department, Universidade Federal de Minas Gerais (UFMG), Belo Horizonte, MG, Brasil

2 Physical therapist

${ }^{3}$ Faculty of Physical Therapy, Universidade Federal de Juiz de Fora (UFJF), Juiz de Fora, MG, Brasil

${ }^{4}$ Universidade Cidade de São Paulo (UNICID), São Paulo, SP, Brasil

Correspondence to: Rosângela Corrêa Dias, Departamento de Fisioterapia, Escola de Educação Física, Fisioterapia e Terapia Ocupacional, Universidade Federal de Minas Gerais,

Av. Antonio Carlos, n 6627, Campus Pampulha, CEP 31270-901, Belo Horizonte, MG, Brasil, e-mail: rcd@ufmg.br 


\section{Introduction $: \because$.}

Fear of Falling (FOF) is recognized as a health problem for the elderly population and can be present even in elders who never fell ${ }^{1,2}$. FOF may lead to a reduction or restriction of functional activities ${ }^{3-6}$ and is associated with adverse outcomes such as falls ${ }^{3,4}$, functional decline ${ }^{5}$ and depression ${ }^{7,8}$.

Activity restriction due to fear of falling when present in excessive level, may provide loss of independence for reducing the social interaction, which in turn lead to physical inactivity and reduced quality of life ${ }^{4,5,7,9}$. Activity restriction is a predictor of falls, possibly because of the unchaining decline of muscle function, physical deconditioning, balance and gait desorders ${ }^{3,10}$.

Individual characteristics may affect or modulate changes in the behavior associated with FOF, which may lead to the development of protection attitudes and caution in relation to falls that allow elders to manage their fear without restricting activities $^{4,9-12}$. Deshpandeet al. ${ }^{11}$ suggest that depression may modulate the factors that affect activity restriction due to fear of falling. Murphy, Williams and Gill ${ }^{9}$ identified that elders who restrict activities due to fear of falling show worse physical capacity and are more anxious and depressed. Other studies report that these elders have a restricted social support network ${ }^{6,13}$. In this context, psychological and physical-functional factors contribute to activity restriction due to fear of falling.

Thus, considering the negative impact of FOF and activity restriction on the physical and mental condition of elders, there is a need to investigate which factors (potentially modifiable) could contribute to activity restriction due to fear of falling. Therefore, this study had the objective to determine the social-demographic, clinical, functional and psychological factors associated with activity restriction due to fear of falling in community-dwelling elderly and identify which one of these variables best discriminate groups of patients with different activity restriction and fear of falling.

\section{Methods $: \because$.}

This was a cross-sectional study, with a sample of elders recruited in the Elders Reference Center and in health basic units placed in Belo Horizonte, MG, Brazil. The following inclusion criteria were used: aged 65 years or more; both genders; be clinical stable; be able to walk alone and using or not a walking aid device. All patients signed an informed consent term before inclusion. Individuals with neurological conditions that prevented the performance of tests and those with the possibility of cognitive deficit, according to the scores of Mini Mental State Examination ${ }^{14}$ were excluded. The sample size calculation was based on a pilot study with 18 elders, considering a power of $80 \%$ and significance level of 5\%. This study was approved by the Ethics in Research Committee of the Universidade Federal of Minas Gerais (UFMG), Belo Horizonte, MG, Brazil (protocol no. 610/07).

\section{Measures}

The volunteers responded to a one time only interview conducted by examiners previously trained. The evaluation of anthropometrical measures, clinical information and socialdemographic data were collected at the beginning.

The Brazilian version of the Survey of Activities and Fear of Falling in the Elderly (SAFFE) questionnaire ${ }^{15}$, was used to evaluate fear of falling and activity restriction due to fear of falling in 11 activities performed inside and outside home. The fear score was computed as the average worry scores across the 11 activities, ranging from 0 to 3 per activity. Larger value represents higher worry with the possibility of falling. The activity restriction score ranging from 0 to 11 was calculated by the sum of the number of activities that were reported to have been performed "less than used to" or were not executed due to FOF. Based on the SAFFE results, the elders were classified into three groups: "No Fear of Falling", "Fear of falling alone" and "Activity restriction due to fear of falling".

FOF was also evaluated by the question: "In general, do you fell afraid of falling? with four answer categories: "no", "a little", "moderate" and "a lot". The occurrence and frequency of falls in the prior year were also recorded.

Falls-related Self-Efficacy was measured using the Brazilian version of Falls Efficacy Scale-International (FES-I Brazil). The questionnaire evaluates the worry associated with the possibility of falling when performing 16 activities, with scores from 1 to 4 points per activity. The total score is obtained by the sum of the scores in all activities, ranging from 16 to 64 points, in which the higher value indicates lower self-efficacy ${ }^{16}$.

Frailty phenotype was evaluated by five domains: 1) unintentional weight loss ( $\geq 4.5 \mathrm{Kg}$ or $\geq 5 \%$ of body weight in prior year); 2) exhaustion, evaluated by self-report of fatigue through two questions of the Center Epidemiological Studies - Depression (CES-D); 3) decreased grip strength of the dominant hand, measured by the JAMAR dynamometer (NC 701/142 model) and adjusted for gender and body mass index; 4) low physical activity level, measured by kilocalories expenditure per week and adjusted for gender (Brazilian version of Human Activity Profile) ${ }^{17}$ and 5) gait slowness evaluated by the time spent in seconds to walk 4.6 meters adjusted for gender and height. Individuals with three or more positive criteria were considered frail; individuals with one or two positive criteria were considered pre frail and those with no positive criteria were considered non frail ${ }^{18}$.

Functional capacity was evaluated using performance measures and self-reported questionnaire. The Brazilian 
version of the Short Physical Performance Battery (SPPB) ${ }^{19}$ was used. This test is composed by three tests that evaluate balance, gait speed and an indirect measure of muscle strength of lower limb sthrough the movement of sit to stand performed five consecutive times ${ }^{20}$. The score for each test ranges from zero (worse performance) to four points (better performance). The SPPB total score is obtained by the sum of the scores in the three tests, ranging from zero to 12 points $^{20}$. For the selfreport measures, the elders' performance was evaluated using the basic activities of daily living (BADL) through the Brazilian version of the Katz index, in which the score ranges from zero (better functional level) to six (worse functional level) ${ }^{21}$, the instrumental activities of daily living (IADL), evaluated through Lawton and Brody ${ }^{22}$ scale, in which the higher the score the better the functional level.

The advanced activities of daily living were evaluated by self-report through a structured questionnaire. Individuals answered how often (never did/have stopped doing /still do) they performed 12 activities of social nature.

Depressive symptoms were evaluated using the reduced Brazilian version of the Geriatric Depression Scale (GDS-15), with a cut-off of 5/6 (non depressed/depressed) ${ }^{23}$. Health self-perception was evaluated subjectively through the selfreported variables of perceived health and global satisfaction with life referenced by domains ${ }^{24}$.

\section{Statistical analysis}

Descriptive analyses of the variables of the study with a significance level of $\alpha=0.05$ were conducted. KolmogorovSmirnov (K-S) test was used to verify the data normality. The qui-square test was used to evaluate the association between nominal variables and in those for which the use of the test was not possible the $\mathrm{Z}$ test was applied. Analyses of Variance
(ANOVA) were used to compare the means of the three groups. The lineal trend between groups according to the activity restriction profile was also evaluated. Analysis of variance of Kruskal-Wallis was used to compare ordinal variables between more than two groups.

CHAID method ${ }^{25}$ was used to verify which variables better discriminated the groups in relation to activity restriction. The Bonferroni model was used to determine statistical significance level. The model validity was verified using a splitfolds to partition the model in several samples and to verify if the predictive power was compatible in the sub-samples when compared with the model for the whole sample. The data analysis was performed on SPSS for Windows (version 15.0) and G*Power (version 3.1) programs.

\section{Results $: \because$.}

One hundred and thirteen community-dwelling elderly, functionally independent, with mean age of $74.5 \pm 7$ yrs participated in the study. In total $85 \%$ were women, $45 \%$ were widowers, $42 \%$ were mulatto and $38 \%$ lived alone.

More than $70 \%$ of the elders did not graduate from primary school and the mean years of education was $4.4 \pm 3.4 \mathrm{yrs}$. Twenty-two elders (19.46\%) reported no FOF, 32 (28.32\%) reported only FOF and 59 (52.22\%) reported FOF and reduction of activities due to this fear.

The frequencies for each of the 11 evaluated activities by SAFFE are presented in Table 1. More than $80 \%$ of the participants reported to perform nine of the 11 activities explored by SAFFE. The mean value of FOF for each of the activities is also in Table 1.

The highest FOF values were observed in the activities "to walk on slippery superficies" and "to take shower". Regarding activity restriction, at least $45 \%$ of the participants reported

Table 1. Descriptive data of The Survey of Activities and Fear of falling in the Elders sub-scales ( $n=113$ ).

\begin{tabular}{lccc}
\hline Activity & $\begin{array}{c}\text { Who do activity } \\
\%(\mathrm{n})\end{array}$ & $\begin{array}{c}\text { Who do activity less than } \\
5 \text { years ago } \%(\mathrm{n})\end{array}$ & $\begin{array}{c}\text { Fear of falling } \\
(\text { mean } \pm \text { SD) }\end{array}$ \\
\hline 1. Go to the store? & $96.5 \%(109)$ & $46 \%(52)$ & $0.51 \pm 1.00$ \\
\hline 2. Prepare simple meals? & $99.1 \%(112)$ & $37.2 \%(42)$ & $0.11 \pm 0.49$ \\
\hline 3. Take a shower? & $100 \%(113)$ & $4.4 \%(5)$ & $0.61 \pm 1.05$ \\
\hline 4. Get out alone of bed? & $99.1 \%(112)$ & $16.8 \%(19)$ & $0.41 \pm 0.83$ \\
\hline 5. Take a walk for exercise? & $53.1 \%(60)$ & $41.6 \%(47)$ & $0.43 \pm 0.91$ \\
\hline 6. Walk on slippery superficies? & $78.8 \%(89)$ & $49.6 \%(56)$ & $1.61 \pm 1.24$ \\
\hline 7. Visit a friend or relative? & $93.8 \%(106)$ & $43.4 \%(49)$ & $0.41 \pm 0.88$ \\
\hline 8. Reach for something over your head? & $92.9 \%(105)$ & $40.7 \%(46)$ & $0.43 \pm 0.95$ \\
\hline 9. Go to a crowded place? & $80.5 \%(91)$ & $53.1 \%(60)$ & $0.27 \pm 0.76$ \\
\hline 10. Walk several blocks outside? & $92 \%(104)$ & $44.2 \%(50)$ & $0.58 \pm 1.03$ \\
\hline 11. Bend down to get something? & $89.4 \%(101)$ & $45.1 \%(51)$ & $0.39 \pm 0.93$ \\
\hline
\end{tabular}

* higher scores indicate grater fear of falling (range 0-3). 
that they walked on slippery superficies, went to a crowed place or bent down to get something less frequently than they used to do five years ago.

Table 2 shows the classification results of each SAFFE item according to the degree of activity restriction. The activities more restricted due to FOF were: to walk on slippery superficies, to walk outside for several blocks and to reach something over the head.

Table 3 shows the variables associated with activity restriction due to fear of falling. Out of the participants with

Table 2. Classification according to fear of falling and activity restriction of The Survey of Activities and Fear of falling in the Elders ( $\mathrm{n}=113)$.

\begin{tabular}{lccc} 
Activity & $\begin{array}{c}\text { No fear of Falling } \\
\%(\mathrm{n})\end{array}$ & $\begin{array}{c}\text { Fear of Falling } \\
\text { Fear of falling alone } \\
\%(\mathrm{n})\end{array}$ & $\begin{array}{c}\text { Activity restriction } \\
\%(\mathrm{n})\end{array}$ \\
\hline 1. Go to the store? & $75.2 \%(85)$ & $12.4 \%(14)$ & $12.4 \%(14)$ \\
\hline 2. Prepare simple meals? & $93.8 \%(106)$ & $2.7 \%(3)$ & $3.5 \%(4)$ \\
\hline 3. Take a shower? & $69.9 \%(79)$ & $29.2 \%(33)$ & $0.9 \%(1)$ \\
\hline 4. Get out alone of bed? & $76.1 \%(86)$ & $20.4 \%(23)$ & $3.5 \%(4)$ \\
\hline 5. Take a walk for exercise? & $76.1 \%(86)$ & $10.6 \%(12)$ & $13.3 \%(15)$ \\
\hline 6. Walk on slippery superficies? & $26.5 \%(30)$ & $38.1 \%(43)$ & $35.4 \%(40)$ \\
\hline 7. Visit a friend or relative? & $78.8 \%(89)$ & $8.8 \%(10)$ & $12.4 \%(14)$ \\
\hline 8. Reach for something over your head? & $79.6 \%(90)$ & $6.2 \%(7)$ & $14.2 \%(16)$ \\
\hline 9. Go to a crowded place? & $86.7 \%(98)$ & $3.5 \%(4)$ & $9.7 \%(11)$ \\
\hline 10. Walk several blocks outside? & $70.8 \%(80)$ & $11.5 \%(13)$ & $17.7 \%(20)$ \\
\hline 11. Bend down to get something? & $83.2 \%(94)$ & $5.3 \%(6)$ & $11.5 \%(13)$ \\
\hline
\end{tabular}

Table 3. Characteristics of participants according to fear of falling level and activity restriction ( $n=113$ ).

\begin{tabular}{|c|c|c|c|c|c|c|}
\hline \multirow[b]{2}{*}{ Variables } & \multicolumn{5}{|c|}{ Restriction groups } & \multirow[b]{2}{*}{$p$ value } \\
\hline & Categories & $\begin{array}{l}\text { No Fear of Falling } \\
\text { (A) }\end{array}$ & $\begin{array}{l}\text { Fear of falling alone } \\
\text { (B) }\end{array}$ & $\begin{array}{l}\text { Activity Restriction } \\
\text { (C) }\end{array}$ & Total & \\
\hline \multicolumn{7}{|l|}{ Functional } \\
\hline Velocity (SPPB) ${ }^{\dagger}$ & & $3.9 \pm 0.4^{c}$ & $3.8 \pm 0.6$ & $3.5 \pm 0.9$ & $3.7 \pm 0.8$ & 0.043 \\
\hline IADL & & $20.7 \pm 0.9 c$ & $20.6 \pm 1.0^{c}$ & $19.9 \pm 1.9$ & $20.2 \pm 1.6$ & 0.017 \\
\hline \multicolumn{7}{|l|}{ Clinical } \\
\hline \multicolumn{7}{|l|}{ Self report of disease in last year } \\
\hline \multirow[t]{2}{*}{ Depression } & Yes & $13.6 \%(3)$ & $12.9 \%(4)$ & $33.9 \%(20)^{\mathrm{ab}}$ & $24.1 \%(27)$ & \multirow{2}{*}{0.038} \\
\hline & No & $86.4 \%(19)^{c}$ & $87.1 \%(27)^{c}$ & $66.1 \%(39)$ & $75.9 \%(85)$ & \\
\hline Number of diseases & & $2.0 \pm 1.2$ & $2.3 \pm 1.4$ & $2.6 \pm 1.6^{a}$ & $2.4 \pm 1.5$ & 0.048 \\
\hline \multicolumn{7}{|l|}{ Psychological } \\
\hline \multicolumn{7}{|l|}{ Perceived health } \\
\hline Present health ${ }^{\ddagger}$ & & $3.0 \pm 1$ & $3.1 \pm 0.9$ & $3.4 \pm 0.8^{\mathrm{a}}$ & $3.3 \pm 0.9$ & 0.040 \\
\hline \multicolumn{7}{|l|}{ Global satisfaction } \\
\hline Capacity of doing and resolving things & & $2.9 \pm 0.3^{c}$ & $2.8 \pm 0.6$ & $2.7 \pm 0.5$ & $2.7 \pm 0.5$ & 0.042 \\
\hline Depression (GDS) & & $1.05 \pm 0.2$ & $1.03 \pm 0.2$ & $1.51 \pm 1.3^{\mathrm{a}}$ & $1.29 \pm 0.98$ & 0.023 \\
\hline \multicolumn{7}{|l|}{ Frailty phenotype } \\
\hline \multirow{2}{*}{ Exhaustion } & Frailty & $4.5 \%(1)$ & $9.4 \%(3)$ & $32.2 \%(19)^{\mathrm{ab}}$ & $20.4 \%(23)$ & \multirow{2}{*}{0.004} \\
\hline & Non frailty & $95.5 \%(21)^{c}$ & $90.6 \%(29)^{c}$ & $67.8 \%(40)$ & $79.6 \%(90)$ & \\
\hline \multirow[t]{3}{*}{ Time to walk 4,6 m (s) } & & $4.7 \pm 1.3$ & $4.6 \pm 1.6$ & $5.9 \pm 3.4^{\mathrm{ab}}$ & $5.3 \pm 2.7$ & 0.033 \\
\hline & Frailty & $4.5 \%(1)$ & $3.1 \%(1)$ & $18.6 \%(11)^{\mathrm{ab}}$ & $11.5 \%(13)$ & \multirow{2}{*}{0.045} \\
\hline & Non frailty & $95.5 \%(21)^{c}$ & $96.9 \%(31)^{c}$ & $81.4 \%(48)$ & $88.5 \%(100)$ & \\
\hline \multicolumn{7}{|l|}{ Falls } \\
\hline FES-I (total) & & $17.86 \pm 1.4$ & $22.56 \pm 4.3^{\mathrm{a}}$ & $27.78 \pm 7.7^{\mathrm{ab}}$ & $24.37 \pm 7.1$ & 0.000 \\
\hline Fear of falling (question) & & $1.5 \pm 0.9$ & $2.6 \pm 1.3^{a}$ & $3.4 \pm 0.9^{\mathrm{ab}}$ & $2.8 \pm 1.2$ & 0.000 \\
\hline
\end{tabular}

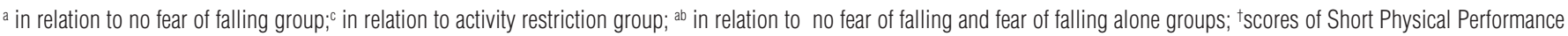
Battery: lower(0)-doesn't finish the test; Higher (4)-velocity $\geq 0.83 \mathrm{~m} / \mathrm{s}$ or time <4.82s; ${ }^{\ddagger}$ categories: 1-excellent; 2-very good; 3-good; 4-regular; 5-very bad. 
FOF, those who reported activity restriction showed greater self-report of depression $(\mathrm{p}=0.038)$ and lower fall-related selfefficacy $(\mathrm{p}=0.000)$ in comparison with those who did not restrict their activities. When compared with the elders who did not report FOF, the participants who restricted activities due to fear of falling demonstrated lower gait speed, lower independence level to perform IADL, lower satisfaction with their capacity to do and to solve daily situations, higher number of diseases, worse health self-perception, greater presence of depressive symptoms and lower fall-related self-efficacy $(\mathrm{p}<0.05)$. The groups did not show significant differences regarding the social-demographic characteristics.

With relation to the frailty phenotype criteria, the elders who belonged to the group which reported FOF and activity restriction and those who had positive result for exhaustion and gait slowness and lower vitality and higher time spent to walk 4.6 meters respectively, when compared with the other two groups (Table 3). Associations between activity restriction due to fear of falling and the different frailty profiles were not observed.

The three groups were statistically different in relation to FOF evaluated using the question about fear intensity. The group that reported FOF and activity restriction demonstrated higher levels of fear when compared with the other groups. Association between activity restriction and occurrence of falls in the previous year was not observed.

On the analysis to verify which variables better discriminated the groups in relation to activity restriction due to fear of falling, the variables that had a high expected correlation for these criteria (fall-related self-efficacy and FOF) were excluded. The variables that best discriminated the groups were depression, exhaustion and participation in social activities, demonstrated in the diagram (Figure 1).

For the grouping obtained through the CHAID method, it may be observed that the first distinctive characteristic was depression, evaluated using GDS. Those with positive symptoms for depression showed $90 \%$ chance of restricting activities due to fear of falling. Out of the elders that did not have depressive symptoms, those who had positive result for exhaustion of the frailty phenotype had $78 \%$ chance of restricting activities due to fear of falling. Out of the ones who did not show positive result for exhaustion, the other distinctive characteristic was participation in social activities. Those who stopped performing activities had $73 \%$ chance of restricting activities due to fear of falling.

\section{Discussion $\because \because$.}

This study points out that elders who reported activity restriction due to fear of falling had slower gait, showed worse performance in IADL, greater number of diseases and self-report of depression, lower fall-related self-efficacy, worse health self-perception and greater presence of depressive symptoms. Among the social-demographic, clinical, functional and psychological variables, the depressive symptoms, exhaustion and participation in social activities discriminated better the elders who restricted activities due to fear of falling from those who did not restrict them.

About $45 \%$ of the participants reported having reduced the performance of the evaluated activities in relation to the last five years, except for the items "to take shower and "to get out alone of bed". The percentage of individuals who reported having reduced the frequency of these activities due to the fear of falling was relatively low. A possible explanation would be that in a situation of risk of falling, the elders could adapt through environmental or behavioral changes, failing to perceive and consequently report the $\mathrm{FOF}^{6}$.

In addition to the worry about the damage of social image and with the functional disability ${ }^{26}$, personal preferences for not performing the activity, physical limitations, environmental barriers and financial and/or transport problems ${ }^{5}$, modifications in the task execution ${ }^{27,28}$ and pain $^{28}$ are other reasons identified in the literature for the occurrence of activity restriction and difficulty in the performance of mobility tasks in community-dwelling elderly. Therefore, it is possible that other factors, besides FOF, may contribute to change in mobility pattern and restriction of activities in elders.

The prevalence of activity restriction of $57 \%$ of the elders who reported FOF corroborates several studies ${ }^{6,11,12,29,30}$, although lower prevalence were identified in this study ${ }^{4,9,31,32}$. These variations may be due to the use of different questionnaires for measuring activity restriction and to the differences in the characteristics of the evaluated population ${ }^{29,31}$.

The lower gait speed observed in the group that reported activity restriction due to fear of falling matches the literature ${ }^{9-11,29}$. Gait is a necessary ability to perform the activities of daily living. Considering that mobility tasks are frequently restricted on elders ${ }^{4}$, it is possible that the longer time spent to walk certain distance by those who restricted activities due to fear of falling has happened due to the decline of physical capacities associated with physical inactivity and with social isolation ${ }^{4,6,9}$.

There was no association between activity restriction due to fear of falling and performance in SPPB. It is possible that the activity avoided by the elders has not influenced their performance in this test, once the activity more restricted due to FOF among the participants was "to walk in slippery superficies".

The difference in difficulties to perform IADL and activity restriction between the three groups was similar to those that had already been reported in studies on activity restriction due to fear of falling in community elderly $y^{9,29,31,33}$. There was no 


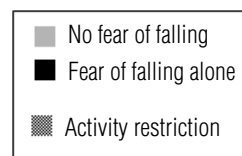

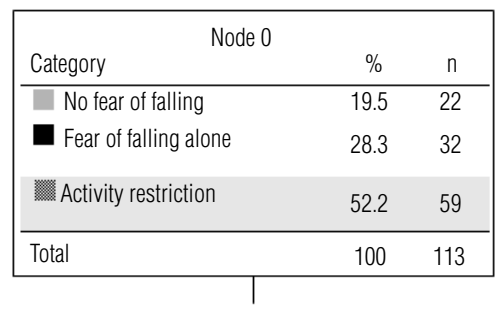

Depression (GDS)

Adj. P-value $=0.004$, Chi-square $=15.153, \mathrm{df}=2$

$\leq 5$

1

\begin{tabular}{|lcc|}
\hline \multicolumn{2}{|c|}{ Node 1} & \\
Category & $\%$ & $\mathrm{n}$ \\
\hline No fear of falling & 22.8 & 21 \\
Fear of falling alone & 33.7 & 31 \\
Activity restriction & 43.5 & 40 \\
\hline Total & 81.4 & 92 \\
\hline
\end{tabular}

EXHAUSTION

Adj. P-value $=0.010$, Chi-square $=9.184, \mathrm{df}=2$

\begin{tabular}{|lcc|}
\multicolumn{2}{c}{ Frailty } \\
\hline \multicolumn{3}{|c|}{ Node 3} \\
Category & $\%$ & $\mathrm{n}$ \\
\hline No fear of falling & 0.0 & 0 \\
Fear of falling alone & 21.4 & 3 \\
Activity restriction & 78.6 & 11 \\
\hline Total & 12.4 & 14 \\
\hline
\end{tabular}

Take part in social meetings, parties or dances Adj. P-value $=0.016$, Chi-square $=10.437, \mathrm{df}=2$

\begin{tabular}{|c|c|c|c|c|c|}
\hline \multicolumn{3}{|c|}{ Never did or still doing the activity } & \multicolumn{3}{|c|}{ Have stopped doing the activity } \\
\hline \multicolumn{2}{|c|}{ Node 5} & & \multicolumn{3}{|c|}{ Node 6} \\
\hline Category & $\%$ & $\mathrm{n}$ & Category & $\%$ & $\mathrm{n}$ \\
\hline No fear of falling & 30.2 & 19 & No fear of falling & 13.3 & 2 \\
\hline Fear of falling alone & 41.3 & 26 & Fear of falling alone & 13.3 & 2 \\
\hline Activity restriction & 28.6 & 18 & Activity restriction & 73.3 & 11 \\
\hline Total & 55.8 & 63 & Total & 13.3 & 15 \\
\hline
\end{tabular}

Figure 1. Agglomeration method (CHAID) for restriction activity groups ( $n=113)$.

association between activity restriction due to fear of falling and difficulties in BADL. The literature reports contradictory results in relation to $\mathrm{BADL}^{9,29,33}$, possibly due to the use of different questionnaires to assess variable. The associations observed in the present study evidence the hierarchical loss of the functional abilities which occurs in aging and happens from IADL to BADL ${ }^{34,35}$. Therefore, it is possible that the elders who restrict activities by FOF and those who do not restrict have similar abilities in the performance of BADL, but not in more complex activities such as IADL.
The participants who restricted activities by FOF showed a worse evaluation of health and, in relation to global satisfaction with life, a lower satisfaction with the capacity to do and to solve routine activities. In a Brazilian study ${ }^{34}$, it was observed that having disability for at least one BADL reduced in half the probability of scoring health as excellent or good. Some studies on health perception and activity restriction due to fear of falling demonstrated similar results to the present study ${ }^{12,13,29,30}$, however, Martin et al. ${ }^{31}$ did not observe similar results. The difference between studies could have occurred 
due to the different characteristics of the evaluated population. Additionally, in the present study, the self-perception of health was evaluated by a larger number of dimensions than the ones reported by Martin et al. ${ }^{31}$.

Similar to the results of Wilson et al. ${ }^{29}$, the elders who restricted activities by FOF showed higher number of chronic diseases when compared with the ones who did not report FOF. Murphy, Williams and Gill ${ }^{9}$ demonstrated that the presence of two or more chronic diseases were associated with elders who restricted activities by FOF. The literature reports the association between activity restriction and hypertension ${ }^{31}$, heart disease $\mathrm{s}^{13}$, osteoporosis and arthritis ${ }^{13,31}$ in elders.

Regarding frailty profiles, no differences were observed between the three groups. Murphy, Williams and Gill ${ }^{9}$ observed greater physical frailty and comorbidities in elders who restricted activities by FOF in relation to those who just reported fear. In the same way, Wilson et al. ${ }^{29}$ also observed a worse functional status in elders who reduced activities by FOF in relation to the others. In the present study, elders who restricted activities by FOF, in spite of showing a worse functional status and higher number of chronic diseases, weren't more frail than the others, considering that frailty, functional disability and comorbidities may show a causal relationship although they represent clinically distinct entities ${ }^{36}$.

There was no relationship between history of falls and the three analyzed groups, although strong associations were observed between activity restriction and fall-related self-efficacy and FOF. Fall and FOF are strongly correlated and an individual who shows one of these outcomes is in high risk of developing the other ${ }^{3}$. Additionally, elders who restrict activities by FOF are in high risk of becoming fallers because activity restriction may lead to functional decline and increased risk of future falls ${ }^{3}$. Possibly, there is a relationship between falls and FOF, but this was not detected in the activity restriction assessed in this study. It is possible that the participants of this study have a greater resilience or perceived less the risks of falls and because of that they restricted less their activities, or still, it may be possible that the fear perceived is not enough to provoke decrease of activities in this population.

The variables strongly associated with activity restriction due to fear of falling were depression, exhaustion and participation in social activities, demonstrating that psychossocial factors are important in activity restriction. However, other studies $^{31,37}$ observed that in spite of being more prevalent in elders with activity restriction due to fear of falling, the adverse psychological factors did not have independent associations with activity restriction in elders.

Depression was the first discriminatory factor indicating that elders with positive result for the GDS scale had greater chance of restricting their activities FOF. Studies identified that depressive symptoms were associated with activity restriction ${ }^{9,10,30}$. Additionally, the presence of depressive symptoms seems to modulate the factors that are associated with activity restriction due to fear of falling ${ }^{11}$. A greater risk for depression has been associated with inadequate evaluation of coping self-efficacy in stressful events of life ${ }^{38}$. It is worth noting that the participants of the present study who restricted activities by FOF showed lower self-efficacy in relation to the other participants. Thus, it is possible that elders with depressive symptoms perceive them selvesless capable of performing certain tasks and, because of that, restrict their activities.

The second discriminate factor was exhaustion, which indicates that, among the elders who did not have depressive symptoms, those who scored for this item in the frailty phenotype had greater chance of restricting activities by FOF. According to Santos ${ }^{39}$, pre frail and frail elders have greater difficulty in performing BADL and IADL than non frail elders. Additionally, the presence of the exhaustion criteria, together with physical inactivity and gait slowness demonstrate high sensitivity for the classification of elders as frail ${ }^{39}$.

Participation in social activities was the last discriminatory factor for the studied sample; however this variable did not show association with activity restriction in the bivariate analysis. It is possible that this difference in relation to the participation in social activities only occurs for a subgroup and not for the whole sample.

Three clinical variables were capable to discriminate the participants according to the groups of activity restriction. Such variables are of easy measuring and can be incorporated to clinical practice to favor the early identification of elders with activity restriction due to fear of falling and the elaboration of therapeutic measures to prevent the occurrence of unfavorable health conditions.

\section{Conclusion $\because \because$.}

Activity restriction due to fear of falling is associated with negative effects in psychological and functional aspects of community elders. Depressive symptoms, exhaustion and the non-participation in social activities discriminated the activity restriction due to fear of falling better than the physical-functional factors.

\section{Acknowledgments $: \because$}

To the Conselho Nacional de Desenvolvimento Cientifico e Tecnológico (CNPq) and to the Fundação de Amparo a Pesquisa do Estado de Minas de Gerais (FAPEMIG), for the financial support. 


\section{References $: \because$.}

1. Legters K. Fear of falling. Phys Ther. 2002;82(3):264-72.

2. Scheffer AC, Schuurmans MJ, van Dijk N, van der Hooft T, de Rooij SE. Fear of falling: measurement strategy, prevalence, risk factors and consequences among older persons. Age Ageing. 2008;37(1):19-24.

3. Friedman SM, Munoz B, West SK, Rubin GS, Fried LP. Falls and fear of falling: which comes first? A longitudinal prediction model suggests strategies for primary and secondary prevention. J Am Geriatr Soc. 2002;50(8):1329-35.

4. Delbaere K, Crombez G, Vanderstraeten G, Willems T, Cambier D. Fear-related avoidance of activities, falls and physical frailty. A prospective community-based cohort study. Age Ageing. 2004;33(4):368-73

5. Lachman ME, Howland J, Tennstedt S, Jette A, Assmann S, Peterson EW. Fear of falling and activity restriction: the survey of activities and fear of falling in the elderly (SAFE). J Gerontol B Psychol Sci Soc Sci. 1998;53(1):43-50.

6. Howland J, Lachman ME, Peterson EW, Cote J, Kasten L, Jette A. Covariates of fear of falling and associated activity curtailment. Gerontologist. 1998;38(5):549-55

7. Arfken CL, Lach HW, Birge SJ, Miller JP. The prevalence and correlates of fear of falling in elderly persons living in the community. Am J Public Health. 1994;84(4):565-70.

8. Burker EJ, Wong H, Sloane PD, Mattingly D, Preisser J, Mitchell CM. Predictors of fear of falling in dizzy and nondizzy elderly. Psychol Aging. 1995;10(1):104-10.

9. Murphy SL, Williams CS, Gill TM. Characteristics associated with fear of falling and activity restriction in community-living older persons. J Am Geriatr Soc. 2002;50(3):516-20.

10. Rochat S, Büla CJ, Martin E, Seematter-Bagnoud L, Karmaniola A, Aminian K, et al. What is the relationship between fear of falling and gait in well-functioning older persons aged 65 to 70 years? Arch Phys Med Rehabil. 2010;91(6):879-84

11. Deshpande N, Metter EJ, Bandinelli S, Lauretani F, Windham BG, Ferrucci L. Psychological, physical, and sensory correlates of fear of falling and consequent activity restriction in the elderly: the InCHIANTI study. Am J Phys Med Rehabil. 2008;87(5):354-62.

12. Zijlstra GA, van Haastregt JC, van Eijk JT, van Rossum E, Stalenhoef PA, Kempen GI. Prevalence and correlates of fear of falling, and associated avoidance of activity in the general population of community-living older people. Age Ageing. 2007;36(3):304-9.

13. Fletcher PC, Hirdes JP. Restriction in activity associated with fear of falling among communitybased seniors using home care services. Age Ageing. 2004;33(3):273-9.

14. Brucki SMD, Nitrini R, Caramelli P, Bertolucci PHF, Okamoto IH. Sugestões para 0 uso do miniexame do estado mental no Brasil. Arq Neuropsiquiatr. 2003;61(3B):777-81.

15. Freire MTF, Santos EGS, Dias RC, Perracini MR. Adaptação para o português e confiabilidade do Survey of Activities and Fear of Falling in the Elderly. Fisioterapia em Movimento. 2011 (submetido)

16. Camargos FFO, Dias RC, Dias JMD, Freire MTF. Adaptação transcultural e avaliação das propriedades psicométricas da Falls Efficacy Scale - Internacional em idosos brasileiros (FESI-Brasil). Rev Bras Fisioter. 2010;14(3):237-43.

17. Souza AC, Magalhaes L de C, Teixeira-Salmela LF. [Cross-cultural adaptation and analysis of the psychometric properties in the Brazilian version of the Human Activity Profile]. Cad Saúde Pública. 2006;22(12):2623-36

18. Fried LP, Tangen CM, Walston J, Newman AB, Hirsch C, Gottdiener J, et al. Frailty in older adults: evidence for a phenotype. J Gerontol A Biol Sci Med Sci. 2001;56(3):M146-56

19. Nakano MM DMFW. Versão brasileira da Short Physical Performance Battery - SPPB: adaptação cultural e estudo da confiabilidade [dissertação]. Campinas: Universidade Estadual de Campinas; 2007.

20. Guralnik JM, Ferrucci L, Pieper CF, Leveille SG, Markides KS, Ostir GV, et al. Lower extremity function and subsequent disability: consistency across studies, predictive models, and value of gait speed alone compared with the short physical performance battery. J Gerontol A Biol Sci

\section{Med Sci. 2000;55(4):M221-31}

21. Lino VTS, Pereira SRM, Camacho LAB, Ribeiro Filho ST, Buksman S. Adaptação transcultura da escala de independência em atividades de vida diária (escala de Katz). Cad Saúde Pública. 2008;24(1):103-12

22. Lawton MP, Brody EM. Assessment of older people: self-maintaining and instrumental activities of daily living. Gerontologist. 1969;9(3):179-86.

23. Almeida OP, Almeida SA. [Reliability of the Brazilian version of the ++abbreviated form of Geriatric Depression Scale (GDS) short form]. Arq Neuropsiquiatr. 1999;57(2B):421-6.

24. Lebrao ML, Duarte YAO. Saúde, bem estar e envelhecimento. 0 projeto SABE no município de São Paulo - uma abordagem inicial. Brasília: Organização Pan-Americana de Saúde/Ministério da Saúde; 2003

25. Kass GV. An exploratory technique for investigating large quantities of categorical data. J Appl Stat. 1980;29(2):119-27

26. Yardley L, Smith H. A prospective study of the relationship between feared consequences of falling and avoidance of activity in community-living older people. Gerontologist. 2002:42(1):17-23

27. Fried LP, Bandeen-Roche K, Chaves PH, Johnson BA. Preclinical mobility disability predicts incident mobility disability in older women. J Gerontol A Biol Sci Med Sci. 2000;55(1):M43-52

28. Gregory PC, Fried LP. Why do older adults decide they are having difficulty with a task? Am J Phys Med Rehabil. 2003;82(1):9-16.

29. Wilson MM, Miller DK, Andresen EM, Malmstrom TK, Miller JP, Wolinsky FD. Fear of falling and related activity restriction among middle-aged African Americans. J Gerontol A Biol Sci Med Sci. 2005;60(3):355-60

30. Curcio CL, Gomez F, Reyes-Ortiz C. Activity restriction related to fear of falling among older people in the Colombian Andes Mountains. Are functional or psychosocial risk factors more important? J Aging Health. 2009;21(3):460-79.

31. Martin FC, Hart D, Spector T, Doyle DV, Harari D. Fear of falling limiting activity in young-old women is associated with reduced functional mobility rather than psychological factors. Age Ageing. 2005;34(3):281-7.

32. Tinetti ME, Mendes de Leon CF, Doucette JT, Baker DI. Fear of falling and fall-related efficacy in relationship to functioning among community-living elders. J Gerontol. 1994;49(3):M140-7.

33. Deshpande N, Metter EJ, Lauretani F, Bandinelli S, Guralnik J, Ferrucci L. Activity restriction induced by fear of falling and objective and subjective measures of physical function: a prospective cohort study. J Am Geriatr Soc. 2008;56(4):615-20.

34. Lebrao ML, Laurenti R. Saúde, bem-estar e envelhecimento: 0 estudo SABE no município de São Paulo. Rev Bras Epidemiol. 2005;8(2):127-41.

35. Maciel ACC, Guerra R0. Influência dos fatores biopsicossociais sobre a capacidade funcional de idosos residentes no nordeste do Brasil. Rev Bras Epidemiol. 2007;10(2):178-89.

36. Fried LP, Ferrucci L, Darer J, Williamson JD, Anderson G. Untangling the concepts of disability, frailty, and comorbidity: implications for improved targeting and care. J Gerontol A Biol Sci Med Sci. 2004;59(3):255-63

37. Kempen GI, Haastregt JC, McKee KJ, Delbaere K, Zijlstra GA. Socio-demographic, health-related and psychosocial correlates of fear of falling and avoidance of activity in community-living older persons who avoid activity due to fear of falling. BMC Public Health. 2009;9:170.

38. Fortes-Burgos ACG, Neri AL, Cupertino APFB. Eventos estressantes, estratégias de enfrentamento, auto-eficácia e sintomas depressivos entre idosos residentes na comunidade. Psicol Reflex Crit. 2008;21(1):74-82.

39. Santos EGS. Perfil de fragilidade em idosos comunitários de Belo Horizonte: um estudo transversal [dissertação]. Belo Horizonte: Escola de Educação Física, Fisioterapia e Terapia Ocupacional, Universidade Federal de Minas Gerais; 2008. 